NAI PROPOSAL NO. 188

\title{
Scientific Spokesman:
}

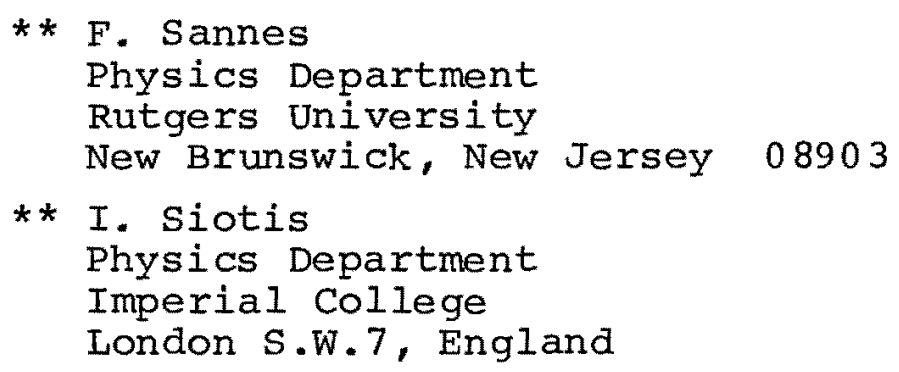

A Proposal to Measure Cross Sections for $\mathrm{pp} \rightarrow \mathrm{pX}, \mathrm{nX}$ as a Function of $\mathrm{s}$ and $\mathrm{M}_{\mathrm{x}}^{2}$ Using the Internal Target Facility at NAL

J. Alspector, K. Cohen, G. Cvijanovich ${ }^{+}$, T. Delillo, B. Maglich, A. Pagnamenta*, B. Robinson, F. Sannes and R. Stanek* Rutgers, the state University of New Jersey

J. Carr, J. Keyne and I. Siotis

Imperial College, London, England

October 24,1972

+Permanent Address:

* Permanent Address: $* *$

Address at NAI:
Upsala College, East Orange, New Jersey

University of Illinois, Chicago, Illinois

27 Winnebago 


\section{NATIONAL ACCELERATOR LABORATORY}

A Proposal to Measure Cross Sections for $p p \rightarrow p X, n X$ as a Function of $\mathrm{s}$ and $\mathrm{M}_{\mathrm{x}}^{2}$ Using the Internal Target

Facility at NAL

J. Alspector, K. Cohen, G. Crijanovich ${ }^{+}$, T. Delillo, B. Maglich, A. Pagnamenta ${ }^{*}$, B. Robinson, F. Sannes and R. Stanek ${ }^{*}$ Rutgers, the State University of New Jersey

J. Carr, J. Keyne and I. Siotis

Imperial College, London, England

Submitted October 24, 1972

\footnotetext{
${ }^{+}$Permanent Address; Upsala College, East Orange, New Jersey

"Permanent Address: University of Illinois, Chicago, Illinois
} 


\section{ADetract}

4. sinnle counter experiment is proposed to investiggte the $s$ and $s / A^{2}$ dependence of the invariant cross section for the alngle perticle inclusive reactions ppopx and $p p \rightarrow n x$ in a Iinited region of phase spece

$$
4<s / n^{2}<20,40<s<s_{n=x}, \quad 0.1<|t|<0.6
$$

near the kinenetic linit. The neatron reaction vill be studied directly, using hyarogen jet, and also by mensuring the differeace between $\mathrm{DP} \rightarrow \mathrm{pX}$ and $\mathrm{DD} \rightarrow \mathrm{pX}$ ising a deuteriun jet. Ine latter vill provide infornotion on the Iine reversed reaction $p n \rightarrow p X$.

The proposed experinent will use the intempl torget and aims to provide inforntion on specific theoretical issues in a very short tiue interval. These issues are: 1) Relative inportence of PPP and PrR complings in the triple Regre frenework.

2) Diffrective versis triple hege epproncines to the understanding of sinfile porticle inclusive repotiona. 
Physicojutiticetion

Theoreticel progress ince 1970 has peverled the phyics interest of single prerticile inclusive distribations. As A result of this progress it is now possible to do sinple expexinents in this tield, covering a very snell region of phase aroce and designed to be relevent to jpecitic theoretical issizes ${ }^{1}$.

Ihis is the spirit of our proposel ard in this context we rin to enswer experinentally a limited number of axetions in $\varepsilon$ very snort tine interval. The guestions ere the following: Can the triple hegge graph provide a ressonobla description of $p p \rightarrow p X a n d p p \rightarrow n z$ at wh energies? If tris is the cese what are tine relative megnitudes of the triple fregge couplings? How do they compre vith values obteined from other experiments (in perticular I Iii)?

A. ditterent enproech to the understonding of single perticle spectra at high energy is that of the "Ditfractive" type models (wireball, Nova, Diffrotive axcitetion etc.) ${ }^{2}$. priple hegse and Diffrective models con lit equaly well the Iull dete on $p p \rightarrow n x^{3}$. Hovever, so we shrll show belon, the two riproches lepd to very diflerent predictions for

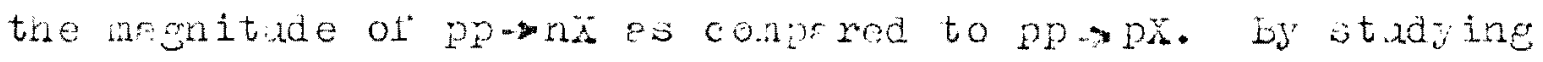
the two rection simateneously we will be rble to difrerentivte between the two types or models. 
Ine iriple resse tporosch

In tre Iinit $s \rightarrow \infty, \Delta^{2} \rightarrow \infty, s / \mu^{2} \rightarrow \infty$ the inverient crosstor $n+b \rightarrow c+x$ is given by ${ }^{4}$ :

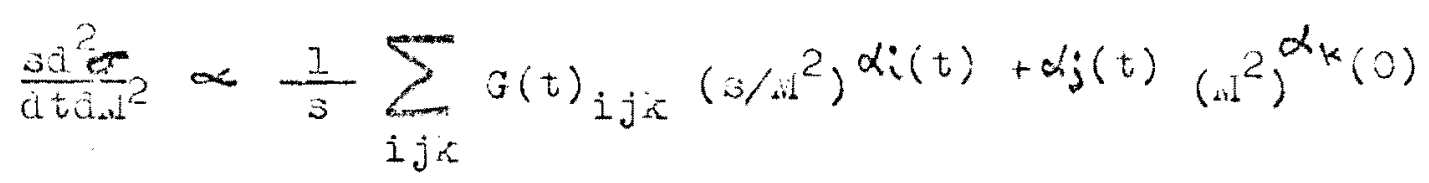

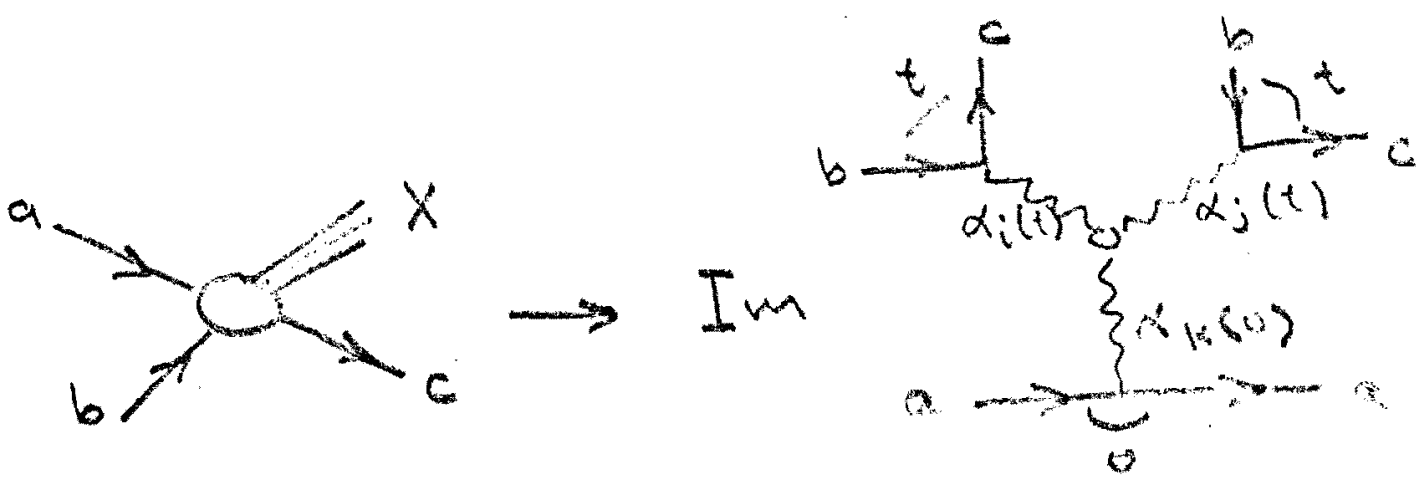

$$
\text { f'is. } 1
$$

where $s=s_{e b}=\left(p_{a}+p_{j}\right)^{2}$

$$
\begin{aligned}
& t=s_{b c}=\left(p_{b}-p_{c}\right)^{2} \\
& i^{2}=s_{e b \bar{c}}=\left(p_{e}+p_{b}-p_{c}\right)^{2} \\
& c_{i j k}(t)=\beta(t)_{i b c} \beta(t)_{j b c} \beta(0)_{k=0} g(t)_{i j k}
\end{aligned}
$$

The assumition lis disally nrae that orosis tems of the Iom $i \neq j$ do not contribate to (1). Lnble 1 gives the functional dependence on $s$ (for $s / w^{2}$ rixed) and on $s / w^{2}$ for s fixed) of the posidible contributions to exprnsion (I). We have restricted the list to terms falling at nost lixe $\mathrm{s}^{-1}$. 
$\underline{\text { irble } 1}$

\begin{tabular}{|c|c|c|c|}
\hline$i j k$ & $\therefore / n^{2}$ & s & We sis zine \\
\hline $2 P$ & $\left(i / w^{2}\right)^{1}+t$ & constrat & \multirow{6}{*}{$\begin{array}{l}\alpha_{P}(t)=1+\frac{1}{2} t \\
\alpha_{R}(t)=\frac{1}{2}+t \\
\alpha_{R}(t)=t\end{array}$} \\
\hline$P R_{2}$ & $(0 / \mathrm{w})^{2} \geq / 2+t$ & $s^{-\frac{1}{3}}$ & \\
\hline $\operatorname{ars}$ & $\left(s / w^{2}\right)^{2 t}$ & constent & \\
\hline ninit & $\left(s / \mathrm{in}^{2}\right)^{1 / 2+t}$ & $s^{-i}$ & \\
\hline$\pi \pi P$ & $\left(3 / 1^{2}\right)^{2 t}-1$ & constrnt & \\
\hline$\pi \pi$ & $\left(s / \omega L^{2}\right)^{2 t}-1 / 2$ & $3^{-3}$ & \\
\hline
\end{tabular}

ny combination of terms in the nove teble can contriwate to pp $\rightarrow p x$. Hovever for pp.six the first two terms are not aloved. Firtieruore for $p p \rightarrow n x$ we heve $i=\rho$ or $A_{2}(I=I)$ wheress for $p p \rightarrow p X$ we cen heve $R=\rho, A_{2}$, w, $f$ excnanges. It is establisned from two body scattering thet the coxpling of the $\mathrm{g}$ and $\mathrm{A}_{2}$ trajectories to the nucleon vertex is mach smeller ${ }^{5}$ then that of $f$ and $\omega\left(g_{g}^{N}=g_{A_{2}}^{N}, g_{f}^{N}=g_{\omega}^{N}, g_{\rho}^{N}=1 / 5 g_{p}^{N}\right)$. If treretore the tirst four couplings in poble 1 are sufficient to describe $p p \rightarrow p X$ we would expect a strong suppression of pp-snd over the region of validity of exprasion ( 1 ).

rigure 2 iliustretes schemsticelly what we snould see in this crae (for ppopx we trice trpical Iin dote). If on the other hend we ovjerve conpareble $p$ and a production nent $x=0.0$ we mast then conciade (in the triple hegge context) 


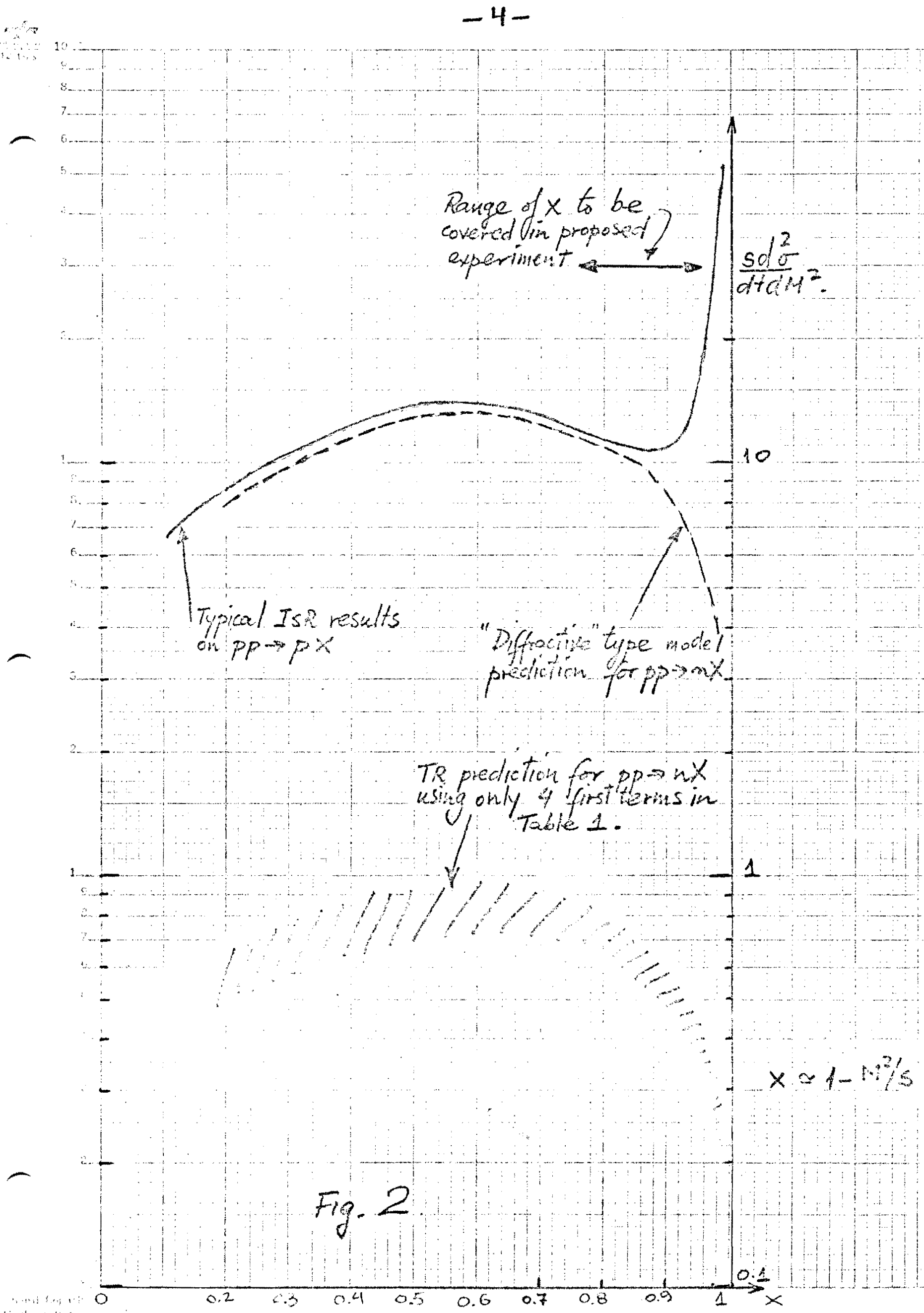


that $\pi m P$ and $T r R$ codplings are very importont for

pp $\rightarrow n x$. juch e oenavior would, et best, be considered ps "eccidentol" in the triple regge Iremework and woxld inply thet the $\pi \pi^{2}$ and $\pi$ rit contributions should not be neglected in tits to ppypX.

In wig. 2 we plso snow tine range of $x$ to be covered by the proposed experimont. Whe rise for $x>0.35$ can be sccunted ror either by the PPY or PPR terms in expansion (1). Mese two tems heve difterent $\mathrm{s}$ dependences and we shell be sble to detemine their relative contriudions.

There are nany difierent theoreticrl conjectares concerning the relative importance of taese couplings 6 (mainly related to the interpretetion of the liereri-ireund diality schene) and experinentel infornetion would be veluable. fig. 3 shows sone predictions for the it energy renge besed on fits to In and sub-AlL energies. The proposed experiment will distingish among these possibilities.

\section{Diffrpctive Ivpe riodeis}

In contrat to triple Regge nodels, Diffroctive nodels" preaict compartile $p$ and n production? ${ }^{2}$ or $x<0.85$. In these nodels the observed perticle spectran is assamed to cone troin the traree grapha of Hig. 4. Hits to InR date of 
$-6-$

TR predictions for sdependance of $p p=0 p X$

$-\frac{s d^{2} \sigma}{d t d u^{2}} A$

$$
t=-0.25(6 \mathrm{er} / \mathrm{c})^{2}
$$

1.2

a.

$$
\begin{aligned}
& 5 / M^{2}=5 \\
& (x=0.8)
\end{aligned}
$$

b.

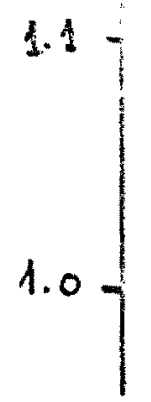

-

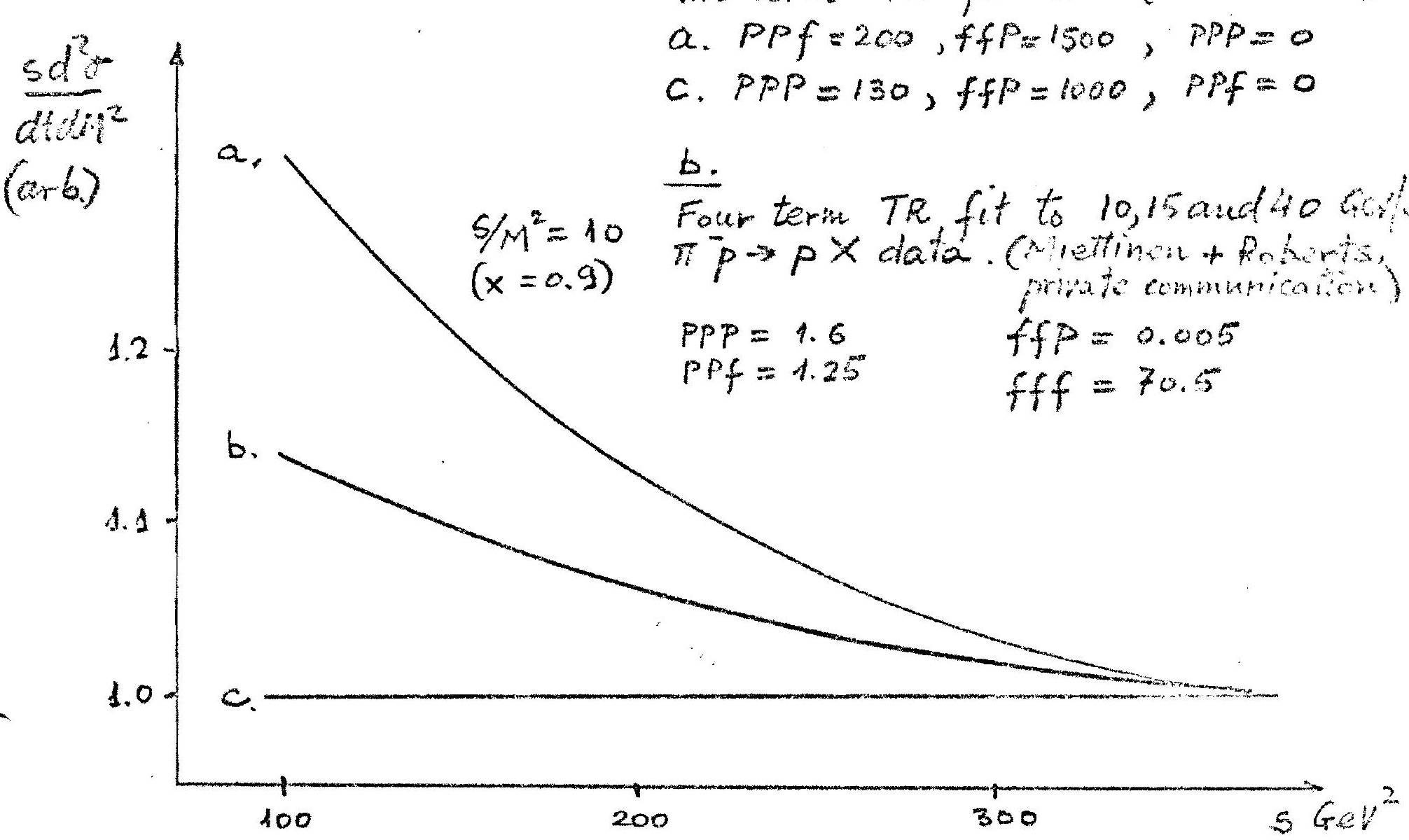

Fig. 3 . 
$-7-$

such models ${ }^{7}$ indicate that for $x<0.85$ graphs $4 b$ and $4 c$ dominate the cross section. In this case the recoil particle cones from the fireball or nov e cascading to its ground state which is equally likely to be $p$ or $n$. The rise nee $x=1$ is accounted for by graph 4 f.

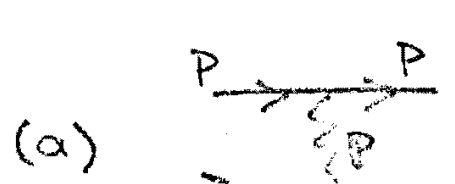

Fireball $P$

(b)

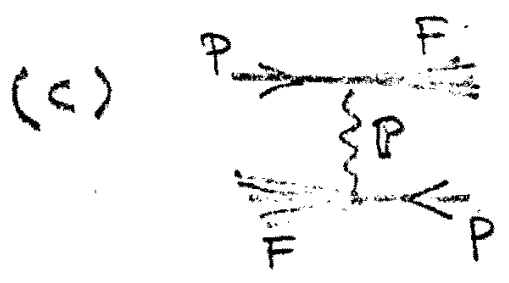

observer.

$$
p
$$$$
\frac{1}{2} p+\frac{1}{2} n
$$$$
\frac{1}{2} p+\frac{1}{2} n
$$$$
\text { Fib. } 4
$$

Summery of Inyizics Justification

By studying $s$ na $s / m^{2}$ dependence of $p p \rightarrow p x$ and

$p p \rightarrow n X$ in a limited region ot phase space we expect to:

1) Jistingilsh between "Diffractive" and "triple Reggae"

type models.

2) Determine in the triple 'rage framework, if it applies, the relative megintaces of the different possible couplings. 
Kinematics

As can easily be shown, at high energy $\left(s=2 \mathrm{mp}_{1}\right)$, the invariant cross section is proportional to the event rate in a fixed solid angle and recoil momentum bite in the laboratory.

$$
\frac{d^{2} \sigma}{d \Omega d p_{c}} \propto \frac{s d^{2} \sigma}{d t d g^{2}}
$$

$s / M^{2}$ is essentially fixed by the recoil lab angle and $t$ by the recoil momentum.

$$
\begin{aligned}
& t=m_{b}^{2}+m_{c}^{2}-2 E_{c} m_{b} \\
& \frac{M^{2}}{s}=\left\{1-\frac{1}{m_{b}}\left(E_{c}-p_{c} \sin \theta\right)\right\} \text { (terms of order } \frac{m^{2}}{s} \text { neglected) }
\end{aligned}
$$

Figure 5 illustrates the region we intend to cover in the proposed experiment. 


$$
p P \rightarrow p x, n x
$$

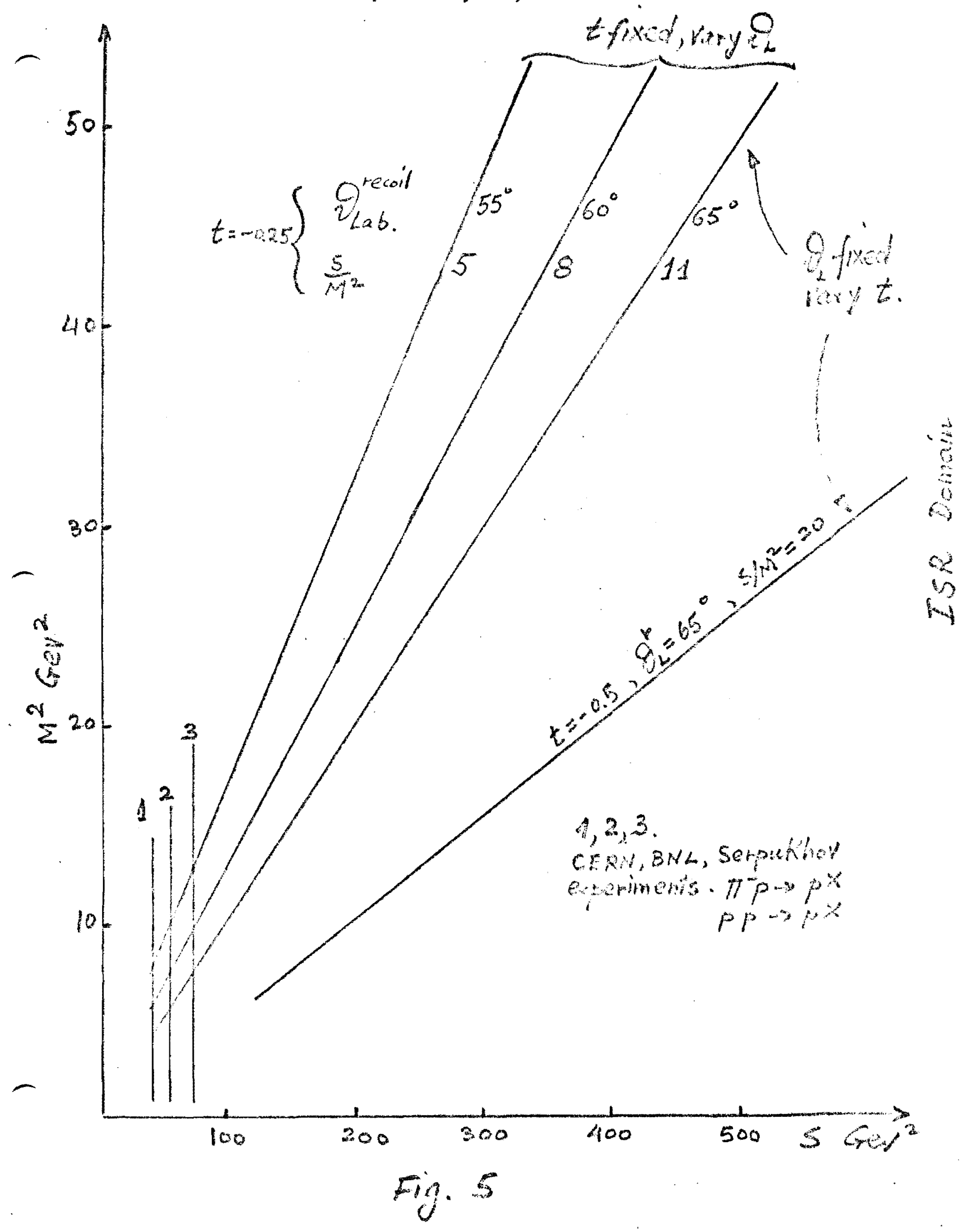


Experinentel hethod

The nethod of detection of the slow recoil protons Pron the resction

$$
p+p \rightarrow p+x
$$

will be similar to that used in experiment $\eta 67$, i.e., the protons are identitied by range, pulse height and tine of figit.

Pwo techniciaes will be used to stidy the physics in

$$
\mathrm{p}+\mathrm{p} \rightarrow \mathrm{n}+\mathrm{x} \text {. }
$$

keaction (3) can be nensired directly by detecting the recoil neutrons prodiced by protons incident on a nydrogen target or one can stady the line reversed refction

$$
p+n \rightarrow p+x
$$

using neutrons in a deuteriam terget and detecting the recoil protons with the same apparatis ased for reection (2). To extract the neutron infornetion one wold need to subtract the effect of the protons in the deuteriam and meke a Glaaber correction. We propose to stady ell three reactions (2), (3) and (4).

the proposed experiment would run in parallel with w experiment 36 (U.A-Uiun collaboretion, po elastic nesr 90\%) and use a great port of the existing set un of WI experinent \#67 (Futgers-Upsala collaboration, pp inelestic). 
lierget

Whe central ferture of the proposed experinent is the use of the circulating proton beam during the acceleration romp in order to study the s dependence of the cross section. This is node possible oy the use of a hydrogen gas jet target located ot section $\mathrm{C}-\mathrm{O}$ of the main ring et $\mathrm{N}$ II. Ey pulsing the jet ot different tines during the ronp it is possible to study all energies between injection ( $B \mathrm{GeV}$ ) and $300 \mathrm{GeV}$. The jet triget duty cycle (i.e., percentage of the acceleratiun cycle during wich the jet can be pulsed) is limited by the efficiency of the cryopunping systen and the gas jet dexsity. A typical figine is $15 \%$ for a ges density of $10^{-7} \mathrm{gm} / \mathrm{cm}^{3}$. Inis duty cycle allows two jet pulses, each lesting $200 \mathrm{~ms}$, et different energies glong the romp. In adaition to hydrogen, the gas jet target hos been succesfully pulsed with deateriun. The circuleting beem profile is an ellipse $2 \times 3 \mathrm{mn}$ ond with o vertical gas jet poot 5 mn in dineter the jet-berm interaection region can be considered ps a point source. 
The Beam

At present the NAL machine operates with single pulse injection. One pulse is $~ 2 \mu s$ long and goes around the machine every $20 \mu \mathrm{s}$. The RF frequency is $53.24 \mathrm{Hc} / \mathrm{s}$ at injection and $53.44 \mathrm{Mc} / \mathrm{s}$ at $200 \mathrm{GeV} / \mathrm{c}$. Each beam pulse is therefore separated into about 100 RF bunches each lasting about 1 ns and occurring every $19 \mathrm{~ns}$. This is a crucial point in our measurement of the recoil neutron monentum.

For a jet duration of $200 \mathrm{~ms}$ the circulating proton pulse will traverse the target $10^{4 .}$ times. At present typical single pulse intensities are about 5-10 10 protons so that $5-10^{14}$ protons will traverse each $200 \mathrm{~ms}$ long jet target pulse. Multipulse injection in the main ring and multiturn injection in the booster are being attempted this month and it is not unrealistic to expect soon an order of magnitude increase in the circulating beam intensity.

\section{The recoil spectrometer}

The proposed experiment will be performed inside the main ring and is therefore severely constrained by space and accessibility limitations.

The recoil spectronleter configuration is sketched in figure 6 . Slow recoil protons are identified by range, pulse height and time of flight in counters $\mathrm{TI}-\mathrm{T} 6$ and N1 - N2. Counters NI and N2 are tapered scintillator blocks and have a dual function. They are to be used as absorbers for recoil protons from $\mathrm{pD} \rightarrow \mathrm{pX}$ or $\mathrm{pD} \rightarrow \mathrm{pX}$, and as detectors for recoi]. neutrons from $p p \rightarrow n x$. The neutron energy will be 


\section{$-13-$}
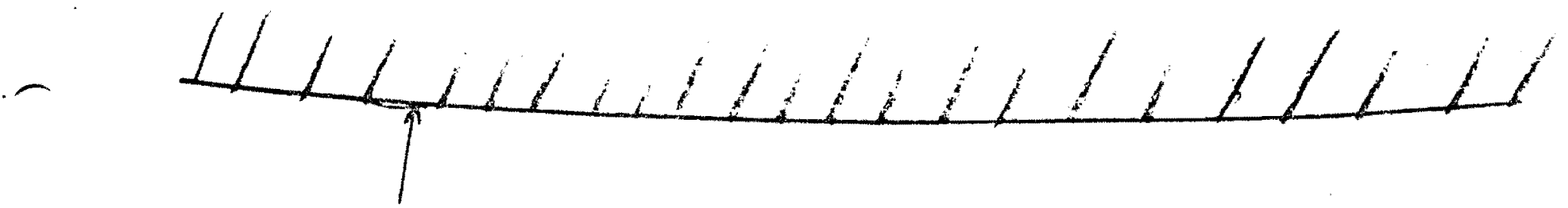

कै

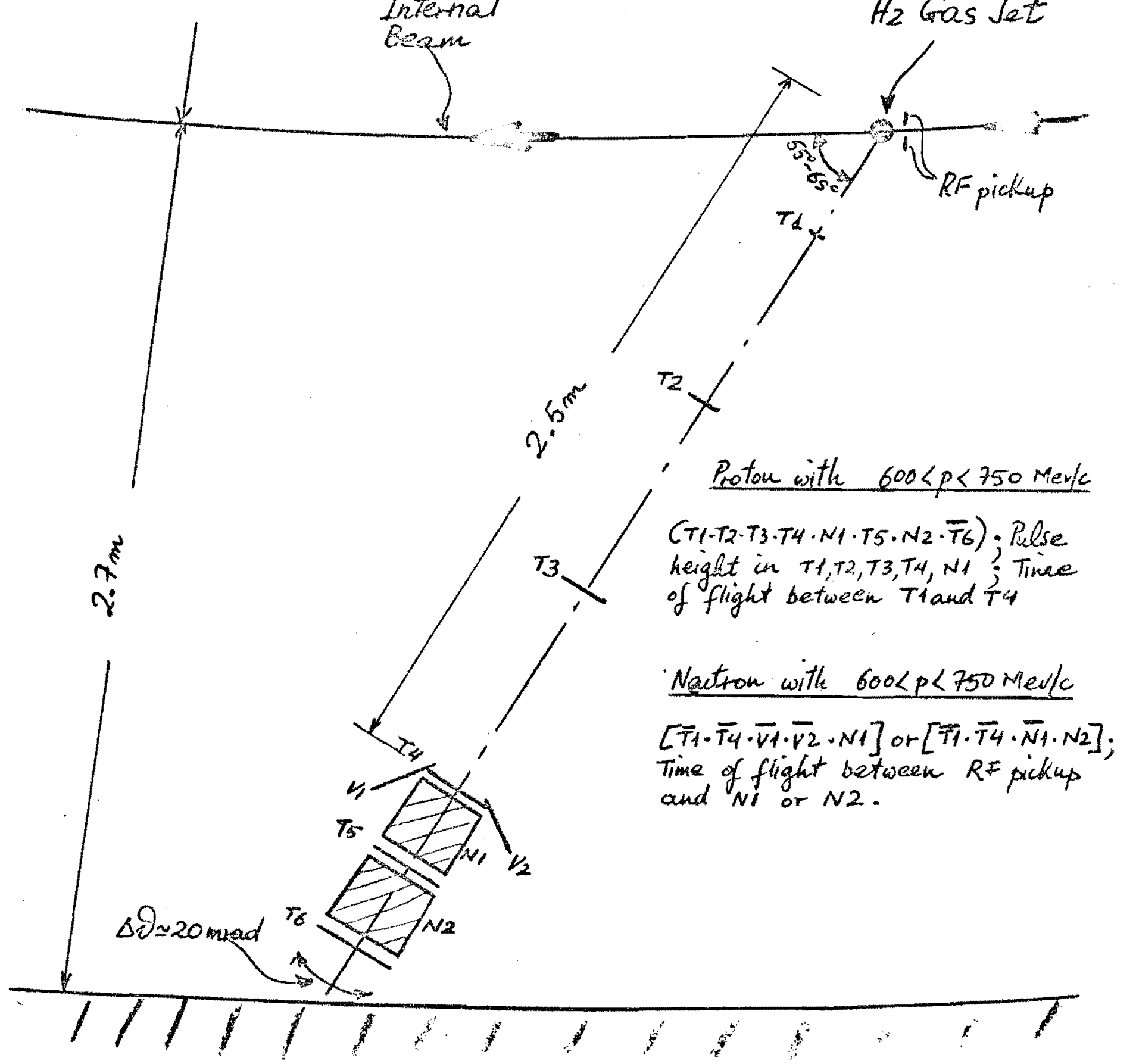

FIG.6. 
determined by time of flight between one RF bunch and detection in the neutron counters. Typical times of flight between target and neutron counters will be about 6 ns after prompt particles. The: neutron time of flight can only be defined modulo 20 ns but this should prósent no ambiguity as neutrons from the previous RE bunch will not have sufficient enengy to trigger the neutron counters.

$\mathrm{N} 1$ and $\mathrm{N} 2$ will each be about $15 \mathrm{~cm}$ long thus leading to detection efficiencies of about $30 \%$ for neutrons with kinetic energy $150<\mathrm{KE}<250 \mathrm{MeV}$. Bias levels for these counters can safely be set at $\$ \mathrm{MeV}$ so that the detection efficiency will not be sensitive to small changes in the bias. By requiring consistency between neutron spectra in counters NI and N2 as a function of incident energy one can investigate non neutron triggers which will not necessarily be the same for the two counters.

\section{Backgrounds}

Slow recoil proton identification is expected to be easy and clean. Preliminary studies using aluminium absorbers instead of $N 1$ and $N 2$ have shown that this is the case. For neutrons we expect to face three types of spurious triggers. Positive $\pi^{\prime} s$ and $K^{\prime} s$ stopping in $N 1$ or $N 2$ will be rejected by the prompt vetos but will give delayed triggers from $\pi^{+}\left(K^{+}\right) \rightarrow \mu^{+} y^{+} \operatorname{lie}^{+} \nu$ which will fake real neutrons say I lis later. lo protect against this the experiment will be inhibited for 3 to 10 us each time a charged particle stops in N1 or N2.

A second possible source of spurious slow neutron triggers may be fast charged or $\gamma$ particles reaching the neutron counters indirectly. This problem can only be studied on site and we intend to deal with it by an appropriato combination of veto counters and shielding blocks. The measured singles rates in counters near the beam pipe are quite low and are due almost exclusively to 
interoctions in tre torget. As the target is a point source it is $e=s y$ to snield the direct poth from torget to neitron detectors by inserting topered lend oricks in the spectroneter. Ine counting rote in the detectors will. then correspond to perticles arriving indirectly from the torget. The pulsed mode of operation of the jet allows the similtaneods inessirement of ndrogen and non-hydrogen events. Ine poirt torget end pulsed mode ore anicue properties of the internal target at in and they vili be fully exploited to identiry neutrons from pp interactions.

wine tnird possible cause of backgroands is $x_{I}^{0}$ particles interocting in the nextron detectors. In the kinemoticol region of the proposed experinent the ratio $p p-s x_{I}^{\circ} X p p \rightarrow p X$ is less then $1 \%$ so thet this possible source of background cen be neglected to tirst order. Finelly, we are =la0 considering the introdaction of a sinall ing gnet in the recoil spectroneter in order to sweep pyay cherged perticles. 
Normalization, Luminosity

As the gas jet is pulsed vertically at a fixed radius and as the circulating beam radius changes during the acceleration ramp and also from pulse to pulse there is a need to monitor the luminosity (how much beam hits how much target) in order to normalise the data. This is even more so as the gas jet density changes slowly as a function of time. We envisage three possibilities to do this.

a. Use an array of scintillators in the forward direction surrounding the beam pipe about $10 \mathrm{~m}$ downstrean of the target which will collect the diffractive part of the total cross section. This monitor will be calibrated using a target made of a thin $(7 \mu)$ carbon filament mounted on a rotating wheel $(60 \mathrm{c} / \mathrm{s})$ and introduced in the circulating beam from below when the jet is not in operation. With this target configuration we can ensure that the carbon filament intercepts fully the beam and we can calibrate the forward monitor against the circulating bean current.

b. Measure the rate of a calculable process such as ep $\rightarrow$ ep. The kinematics for this process is such that at $45^{\circ}$ in the lab. one has 1 Mev electrons which can be identified by a solid state detector telescope.

c. Normalise all rates to the rate of slow $\pi^{ \pm}$in the recoil spectrometer itself. As has been shown by several experiments below $30 \mathrm{GeV}$ and at ISR the invariant cross section for $\mathrm{pp} \rightarrow \pi^{ \pm} \mathrm{X}$ scales in quite a large region of. $s / M^{2}$. In terms or the Feynman variable $|x| \simeq 1-M^{2} / s$ the cross section is independent of $s$ for $.15<|x|<.85$.

The range of $\mathrm{x}$ covered by our spectrometer for the above reaction is $.14<|x|<.18$ which is just at the limit of the scaling region. In fact in this range of $x$ the cross section for reaction $p p+\pi^{+} x$ is independent of $s$ but that for $\mathrm{pp} \rightarrow \pi^{-} \mathrm{X}$ has a non scaling component. As we cannot distinguish between $\pi^{ \pm}$we must rely on other experiments to get the weak $s$ dependence of $\mathrm{pp} \rightarrow \pi^{ \pm} \mathrm{X}$. 
Of the above three possibilities $c$. is the simplest to implement and the most attractive as it automatically takes into account possible s dependent changes in the spectrometer acceptance (for example vertical movement of the beam as a function of $s$ ). Possibility b. will probably be explored by NAL experiment $\$ 36$ ( $\mathrm{pp}$ elastic at $90^{\circ}$ ). We also intend to investigate possibility a. If $a$. or b. can give a reliable monitor of the luminosity our data on $p p \rightarrow \pi^{ \pm} x$ can be used to derive physics information. However, as we want to keep the proposed experiment short in time and simple we may have to rely on $p p \rightarrow \pi^{ \pm} \mathrm{X}$. for normalisation.

Event rates

Preliminary test runs with the equipment of NAL experiment 57 have given very useful information on proton event rates.

For reaction $p p \rightarrow p x$ and for:

-1 jet pulse lasting $200 \mathrm{~ms}$ during ramp $\left(170<\mathrm{P}_{1}<190 \mathrm{GeV} / \mathrm{c}\right)$

$-4 \cdot 10^{10}$ protoris/beam pulse

$-550<\mathrm{p}_{\text {recoil }}<650 \mathrm{MeV} / \mathrm{C}$

we get 2 recoil protons.

In the near future the circulating proton intensity is expected to incrcase by an order of magnitude (multipulse injection in main ring + multiturn injection in booster). Assuming $10^{11}$ circulating protons, $30 \%$ neutron detection efficioncy, $\sigma(p p \rightarrow n x) \sim \frac{1}{3}(p p \rightarrow p X)$ in our kinematical region, we need 200 hours of running to cover 20 energy intorvals and 4 values of $s / M^{2}$ with $5 \%$ statistics for $p{ }^{\prime} \rightarrow \mathrm{n} X$ and $1.5 \%$ statistics for $\mathrm{pp} \rightarrow \mathrm{pX}$. 
Lieterences

1) R. C. Arold, "Iectares on Inclisive Reactions" All prepuint $13 / 7131,1971$. 2. 2. Berser, "Inclasive Experinents, A second alence", Ari prepriat if $/ 7143$, 1971 .

i. Ai. Chen, "tegge Pnenumenology of Inclusive resctions", Cart inder school, irieste, dey 1972.

2) i. I. Berger, Proc, of cont. on iigin znergy Interactions", oxford, 1972 .

3) in. G. Albrow et 41 ., Preprint 940 presented ot the Int'l. Conf. on ris, botevia, sept. 1972.

4) 5. D. Jliis and A. I. Sendf, MAI-TrY-30, 1972.

5) V. Barger and R. J. it. Philjips, Nacl. Phys. 132, 93 (1971). 6) For example: M.B.Einhorm, Wreen, .. A. Viresoro, Phys. Letier: 37E, 292 (1971) deduce from a dupl model that the ppe compling shoujd vanish. Elis and sende in ret. 4) make the conjecture that the PPf end $f(x$ terins snould dominate.

7) $x$. Gottried and 0 . Kofoed-Honsen, to be published in Phys. Letters $B$. The model is outlined in ref. 3). 